relative. The relative risk is simply the risk of someone with this trait as compared to someone without it becoming diabetic. The degree of risk applies only to Caucasians since we did not study other racial groups; there is some ethnic variation in the tendency to flush, ${ }^{10}$ which in the case of flushing after alcohol alone probably has a genetic basis, ${ }^{11}$ so the prevalence of CPAF may also be different in other populations.

In conclusion, we have devised a simple single-dose test for CPAF. CPAF is a dominantly inherited trait associated with non-insulin-dependent diabetes especially when there is a strong family history of the disease. CPAF is not associated with insulin-dependent diabetes, confirming the genetic difference between this and non-insulin-dependent diabetes.

\section{References}

${ }^{1}$ FitzGerald, M G, et al, Diabetes, 1962, 11, 40.

2 Wolff, P H, Science, 1972, 175, 449.

${ }^{3}$ Nerup, J, et al, Lancet, 1974, 2, 846.

${ }^{4}$ Cudworth, A G, and Woodrow, J C, British Medical fournal, 1975, $3,133$.

${ }^{5}$ Tattersall, R B, and Pyke, D A, Lancet, 1972, 2, 1120.

${ }^{6}$ McKusick, V A, in Human Genetics. New Jersey, Prentice-Hall Inc, 1964.

Malins, J M, in Clinical Diabetes Mellitus. London, Eyre and Spottiswoode, 1968.

${ }^{8}$ Woolf, B, Annals of Eugenics, 1954, 19, 251.

${ }^{9}$ Haldane, J B S, Annals of Human Genetics, 1955, 20, 309.

${ }^{10}$ Darwin, C, in The Expression of Emotion in Animals and Man. London, Murray, 1872.

${ }^{11}$ Wolff, P H, American fournal of Human Genetics, 1973, 25, 193.

\title{
Chlorpropamide-alcohol flushing: a definition of its relation to non-insulin-dependent diabetes
}

\author{
D A PYKE, R D G LESLIE
}

British Medical fournal, 1978, 2, 1521-1522

\section{Summary and conclusions}

The single-challenge test for chlorpropamide-alcohol flushing (CPAF) was used to study two groups of patients with non-insulin-dependent diabetes and a family history of the disease who were distinguished only by their age at diagnosis (under and over 30). Their relatives were also studied. The proportions of patients showing CPAF in both groups were similar, and the family histories suggested dominant inheritance. When offspring of diabetics in whom the disease was diagnosed early were studied CPAF seemed to precede the appearance of diabetes.

We conclude that the patients in both groups had the same, distinct syndrome, which is characterised by diabetes diagnosed at any age that is inherited as an autosomal dominant trait and associated with CPAF. This syndrome, which constitutes about one-fifth of all cases of non-insulin-dependent diabetes, may be detected with a single-challenge CPAF test before the onset of glucose intolerance. CPAF therefore acts as a genetic marker for the syndrome.

\section{Introduction}

As shown in the previous paper in this issue, facial flushing after alcohol in patients receiving chlorpropamide is a distinct entity inherited as an autosomal dominant trait. It is found commonly in non-insulin-dependent diabetics, particularly those with a family history of the disease, but only rarely in insulin-dependent diabetics and normal subjects. We have attempted to define the

Diabetic Department, King's College Hospital, London SE5 9RS

D A PYKE, FRCP, consultant physician

R D G LESLIE, MRCP, research fellow relation of chlorpropamide-alcohol flushing (CPAF) to diabetes by studying families of non-insulin-dependent diabetics with a family history of diabetes. Since CPAF is dominantly inherited we have also studied its occurrence in a type of diabetes thought to be inherited in the same fashion-that is, "Mason-type" diabetes $^{1}$ (named after the first family we observed), also called mild diabetes of young onset. ${ }^{2}{ }^{3}$ The evidence that this syndrome is dominantly inherited is, firstly, that in sibships of affected patients half the sibs are also affected; secondly, that nearly all affected subjects have an affected parent; and, thirdly, that several cases of inheritance through three consecutive generations have been seen.

\section{Subjects and methods}

We used the single-challenge test for CPAF (described in our previous paper) to study two groups of non-insulin-dependent diabetics with a family history of the disease: the groups were divided according to age at diagnosis in the belief that patients diagnosed under the age of 30 correspond to those with Mason-type diabetes and are distinct from those diagnosed later. Group 1 comprised 15 propositi diagnosed before the age of 30, and 32 of their parents and sibs, of whom 18 were diabetic and 14 not. Group 2 comprised 37 propositi diagnosed after the age of 30 who had at least two affected first-degree relatives, and 42 of their parents and sibs, of whom 20 were diabetic and 22 not.

\section{Results}

All the 15 propositi and 16 of the 18 diabetic relatives in group 1 flushed, while only two of the 14 non-diabetic relatives did so. In group 2,32 of the 37 propositi and 17 of the 20 diabetic relatives flushed, whereas none of the 22 non-diabetic relatives did so. Thus in group 1 a total of 31 of the 33 diabetics $(94 \%)$ and two of the 14 normal subjects $(14 \%)$ showed CPAF; in group 2 the proportions were 49 of the 57 diabetics $(86 \%)$ and none of the non-diabetic relatives. These results show a strong association between CPAF and diabetes in both groups, the incidence of CPAF being similar in each. Since CPAF is an inherited trait this suggests that diabetes in these selected groups has a genetic basis. If this is so the clinical features of the diabetes will be the same, and we therefore examined the diabetics 
in the two groups with respect to mode of inheritance and insulin dependence.

Mode of inheritance-The family history in both groups suggested dominant inheritance. The evidence for this pattern of inheritance in the families was as follows. In group 1, 68 of the sibs of all affected subjects were diabetic and 68 not; 36 out of 43 affected sibships had diabetic parents, no definite information being available about the remainder; and 12 families showed direct parent-to-child transmission through at least three generations. In group 2, 44 of the sibs of all affected subjects were diabetic and 54 not ; 23 out of 32 affected sibships had diabetic parents (we had no definite information about the remainder); and nine families showed direct parent-to-child transmission through at least three generations.

Treatment-The index cases in both groups had non-insulindependent diabetes. Six out of the 47 living affected relatives in group 1 and eight out of the 69 in group 2 are now receiving insulin, but none is strictly insulin dependent.

Because all the patients in these selected groups had non-insulindependent diabetes inherited as an autosomal dominant and associated with CPAF we re-examined the age and mode of diagnosis of patients and relatives in group 1 to see if they really were different in these respects from ordinary non-insulin-dependent diabetics.

Age at diagnosis-We obtained information about 60 affected relatives of index cases in group 1. The age range at diagnosis was wide (see table); only 21 were diagnosed under the age of 30 .

Age at diagnosis of diabetes of relatives of the 15 propositi diagnosed under age of 30 (group 1)

\begin{tabular}{l|c|c|c|c|c|c|c|c}
\hline Age at diagnosis (years): & $0-10$ & -20 & -30 & -40 & -50 & -60 & -70 & -80 \\
No of subjects: & 4 & 9 & 8 & 14 & 11 & 4 & 6 & 4 \\
\hline
\end{tabular}

Mode of diagnosis-Only five of the 15 propositi had had diabetic symptoms on diagnosis. The rest were diagnosed on routine urine testing, usually carried out because of the strong family history.

These results suggest that early age at diagnosis is not an essential feature of this type of diabetes. Perhaps in families in which diabetes is common children are tested routinely and diabetes diagnosed earlier; in our families most affected offspring were diagnosed earlier (mean age 25) than their affected parents (mean age 38).

Relative times of appearance of CPAF and diabetes-If Mason-type diabetes is inherited as a dominant trait we might be able to diagnose it in early life. In an attempt to do this we tested 18 offspring, who had not already been tested, of 11 Mason-type diabetics. Seventeen offspring aged 4-31 years gave normal results to oral glucose tolerance tests, and one aged 1 month had normal random blood glucose values. Since half of these 18 subjects were presumably genetically diabetic this finding implies that abnormality of glucose tolerance may not be present in early life. Twelve of the 18 were tested for CPAF (the remaining six were under 10 years old or otherwise unsuited to the test), and eight flushed. CPAF therefore seems to precede the appearance of diabetes. This is supported by the cases of two women with non-insulin-dependent diabetes, a strong family history, and CPAF, who were diagnosed at the ages of 32 and 37 but were known to have had normal glucose tolerance seven and four years earlier.

\section{Discussion}

We started this study with two selected groups of non-insulindependent diabetics with a family history of the disease who were distinguished by their age at diagnosis. This distinction now appears artificial. The incidence of CPAF in both groups was virtually the same, and the diabetes, which was mild and free of ketosis, was inherited as an autosomal dominant trait in both. We believe both groups had the same syndrome (Masontype diabetes). This is characterised by non-insulin-dependent diabetes diagnosed at any age, which is dominantly inherited and associated with CPAF.

CPAF appears to precede the appearance of diabetes. When 18 offspring of Mason-type diabetics with CPAF were tested all had normal glucose tolerance, whereas presumably half carried the gene. Of 12 who were tested for CPAF, eight flushed and are presumably destined to develop diabetes. Five diabetic members of these families with Mason-type diabetes did not flush; we have no certain explanation for this. The CPAF test is relatively crude, and we suspect that some dose variation occurs in relation to chlorpropamide and alcohol, so that the singlechallenge test may underdiagnose CPAF. Nevertheless, 33 out of 38 diabetic relatives of the propositi with Mason-type diabetes gave positive results when tested. Only two of the 36 unaffected members of these families flushed; they may have been carriers of the diabetic trait who will develop diabetes in later life. On the other hand, about $10^{\circ}{ }_{0}$, of normal subjects also flush with this test (see previous paper).

We calculate the relative risk of a non-diabetic relative with CPAF developing Mason-type diabetes to be at least $70 .{ }^{45} \mathrm{We}$ suspect therefore that if the offspring of a Mason-type diabetic reacts positively to a CPAF test he is likely to become diabetic, and that the test might be used with considerable confidence to identify a pre-diabetic. To be certain it would be necessary to follow up those offspring of Mason-type diabetics who when tested exhibit CPAF.

The problem remains of how to relate CPAF to non-insulindependent diabetes in patients with no family history. Even in these cases CPAF is commoner than in insulin-dependent diabetics and normal subjects. Furthermore, a family history of diabetes is unreliable: mild diabetes may not be diagnosed until late in life, and family connections may not be maintained. Of all those diabetics who experience $\mathrm{CPAF}, 62^{\circ}{ }^{\circ}$ have a firstdegree family history of diabetes, compared with only $15^{\circ}{ }_{0}$ of those who are CPAF-negative. Presumably most diabetics who show CPAF but have no known family history of diabetes carry the same gene as the Mason-type cases. Non-insulin-dependent diabetes without CPAF is probably a separate entity (or several entities) that, though clinically similar, are genetically different.

If these suggestions are true it follows that non-insulindependent diabetes associated with a first-degree family history of diabetes and CPAF is a distinct syndrome, which we estimate constitutes about one-fifth of all cases of non-insulin-dependent diabetes. It is inherited as an autosomal dominant trait and may be detected with a single-challenge CPAF test before the appearance of glucose intolerance.

RDGL is supported by the Medical Research Council.

\section{References}

${ }^{1}$ Pyke, D A, Clinics in Endocrinology and Metabolism, 1977, 6, 285.

2 Tattersall, R B, Quarterly fournal of Medicine, 1974, 43, 339.

${ }^{3}$ Tattersall, R B, and Fajans, S S, Diabetes, 1975, 24, 44.

${ }^{4}$ Woolf, B, Annals of Eugenics, 1954, 19, 251.

5 Haldane, J B S, Annals of Human Genetics, 1955, 20, 309.

(Accepted 26 October 1978)

ONE HUNDRED YEARS AGO Intelligence having been received from Rustchuk that, notwithstanding the existing agreement to respect hospitals, Russian shells from Giurgevo struck the hospitals at Rustchuk, the English surgeons, at the risk of their lives, conveyed the Turkish wounded to the casemates. In reply, it is alleged that the Russians explain their firing upon the Turkish hospital by a report that upon a shell accidentally falling upon it, three hundred armed Turks rushed out, whereupon they came to the conclusion that the Turks were wrongfully sheltering their barracks under a hospital flag, and so continued their fire upon the building. It is, however, contended that the Russians, at a distance of a couple of miles, could not see whether these two or three hundred poor wretches were or were not armed, and that, admitting their statement to be true, it is explained by the fact that the arms of the wounded are, in the majority of Turkish hospitals, placed near the bed's head, in order that upon recovery, each man may have his own arms, and soldiers finding themselves attacked would naturally catch them up in rushing out. (British Medical fournal, 1878.) 